\title{
Gout treatment and comorbidities: a retrospective cohort study in a large US managed care population
}

\author{
Paola Primatesta ${ }^{1 *}$, Estel Plana ${ }^{2}$ and Dietrich Rothenbacher ${ }^{3}$
}

\begin{abstract}
Background: Gout prevalence increased in recent years to become one of the most common causes of inflammatory arthritis in most industrialised countries. Comorbidities may affect the disease severity and treatment patterns. We describe the main characteristics of gout patients, gout-related treatment patterns and prevalent comorbidities in a managed care population.

Methods: From the large US PharMetrics Patient-Centric Database, patients aged 20-89 with at least 2 claims for a diagnosis of gout (ICD9 274.xx) and related prescriptions between January 1, 1996 and December 31, 2008 were included. Gout flares were ascertained during follow-up. Sex-specific multivariable Poisson regression models were used to assess factors associated with number of flares.
\end{abstract}

Results: 177,637 gout patients were included (mean age 55.2 years; men 75.6\%). Overall, more than half (58.1\%) had any of the considered comorbidities; hypertension (36.1\%), dyslipidemia (27.0\%) and diabetes (15.1\%) being the most common. Nonselective NSAIDs were the most commonly dispensed (in 38.7\% of patients). Notably, 39\% of patients did not receive any prescription medication for gout. Patients with comorbidities were significantly more likely to receive anti-gout prescriptions. During an acute episode the prescription of NSAIDs and colchicine increased; and $29.9 \%$ of patients received allopurinol. The risk of flares was associated with cardiometabolic comorbidities and older age in women (highest at age 60-69), while in men it decreased by age. Women with these conditions were $60 \%$ more likely to have flares (incidence rate ratio, IRR $1.60 ; 1.48-1.74$ ), while men were $10 \%$ (IRR 1.10; 1.06-1.13) more likely.

Conclusions: Comorbidities affected gout treatment patterns and the occurrence and frequency of acute attacks. Cardiometabolic comorbidities, common in this patients' population, were associated with an increased risk of flares.

\section{Background}

Gout prevalence has been increasing in recent years and it is currently one of the most common causes of inflammatory arthritis in most industrialised countries [1]. The increase in the disease prevalence has been linked to increased lifespan, dietary habits, increase in obesity and alcohol consumption; and use of drugs that may raise serum urate levels [1,2]. The most important single risk factor for developing gout is a raised serum uric acid level. Gout results from the deposition of urate

\footnotetext{
* Correspondence: paola.primatesta@novartis.com

'Global Clinical Epidemiology, Novartis Pharma AG, CH-4056 Basel, Switzerland

Full list of author information is available at the end of the article
}

crystals in a joint, leading to an acute inflammatory response. One acute attack may be the only manifestation, or acute inflammatory arthritis episodes (flares), often monoarticular, may recur. If untreated this may lead to chronic gouty arthropathy and deposition of urate crystals in soft tissues, forming tophi.

Acute gout attacks are painful and potentially disabling, needing immediate treatment. The optimal therapy is directed at controlling pain and inflammation $[3,4]$. Drug therapy for gout has become an important part of the therapeutic approach to the disease, which includes lifestyle modifications, and guidelines for its management are available internationally $[5,6]$. Current standards for first-line treatment for acute attacks

\section{Ciomed Central}


include nonsteroidal anti-inflammatory drugs (NSAIDs), colchicine and corticosteroids. Urate-lowering treatment (ULT) (most commonly allopurinol) is usually recommended after the acute attack has resolved.

Despite growing understanding of the disease aetiology and risk factors involved, evidence is accumulating that part of the patient populations is not optimally treated and managed and continue to experience clinical manifestations of gout $[7,8]$. Moreover, suggested firstline therapies are often not well tolerated, and may be contraindicated in some patients due to coexistent medical problems, especially in the elderly, as the majority of these patients have pre-existing conditions such as diabetes, renal, cardiovascular or gastrointestinal diseases $[9,2]$.

The objective of this study was to describe the main characteristics of a large population of patients with gout, their gout-related treatment patterns and prevalent comorbidities and to investigate the frequency and risk factors of flares during follow-up using a managed care population from the US.

\section{Methods}

This retrospective cohort study was conducted in the PharMetrics Patient-Centric Database, an administrative claims database which contains medical and pharmacy claims for $>55$ million patients from $>90$ managed care health plans in the US. Access to the PharMetrics database requires a licence agreement and the data are provided deidentified. Tabulations for these data do not require ethical approval.

Records in the database are representative of the national commercially insured population on a variety of demographic variables, including age, gender, geographic distribution and plan type. The average member enrolment time is 2 years. All patients aged 20-89 years with at least 2 claims (either primary care, office visit or emergency room visit) for a diagnosis of gout (International Classification of Diseases 9th Edition (ICD9) 274. xx) between January 1, 1996 and December 31, 2008 were identified from the anonymized database. The index date was defined as the first occurrence of a gout claim during the study period. Patients were only included in the study if they had been continuously enrolled in the health plan for the period between 6 months before and one year after the index date.

Gout flares were ascertained during the follow-up period. Gout flares were defined as a claim reporting gout as defined above, together with at least one of the following within one week: a) treatment with NSAIDs, colchicine, oral corticosteroids, or adrenocorticotropic hormone (ACTH); b) intraarticular aspiration or injection (Current Procedural Terminology (CPT) codes $206.00,206.05$ or 206.10). Given that an untreated gout flare can last up to a few weeks, each gout flare was estimated to last 30 days and a new flare episode was counted only if it had occurred beyond the 30-day period. The results related to number of flares included a 12 months follow-up period starting 30 days after index date.

Gout medication treatment patterns were identified from the pharmacy claims. Use of NSAIDs (selective/ non-selective), colchicine, corticosteroids (oral or injections), probenecid, and allopurinol was ascertained during a period of 12 months following the index date; and within a week following a flare, to capture drug prescription following an acute episode.

Comorbidities were identified based on the ICD9 codes, during the 6 months before the index date, for claims with a diagnosis of congestive heart failure, ischemic heart disease, hypertension, diabetes, cerebrovascular disease, dyslipidemia, chronic renal failure, gastrointestinal disease, haematological disease, myopathy, osteoporosis.

Data were described using simple descriptive statistics. Sex-specific multivariable Poisson regression models were used to assess factors associated with number of flares. The covariates considered in the multivariable regression model included established risk factors, i.e. age and history of comorbidities (cardiometabolic, gastrointestinal, haematological, myopathy, osteoporosis). All statistical analyses were carried out using SAS (version 9.2).

\section{Results}

Table 1 shows the main characteristics of the 177,637 gout patients included in the study (12 patients were excluded because they had a previous diagnosis of gout within 6 months of the index data). Mean age was 55.2 years (SD 13.1). Men represented the majority of patients $(75.6 \%)$. Overall, more than half $(58.1 \%)$ had any of the considered comorbidities; hypertension (36.1\%), dyslipidemia (27.0\%), diabetes $(15.1 \%)$ and ischemic heart disease (10.2\%) being the most common.

During the 12 months following the index date, 1.2\% of patients were hospitalised at least once and $37.0 \%$ underwent an outpatient visit. In almost one third of patients $(31.8 \%)$ the index visit was carried out at the primary care physician office; in only $2.7 \%$ it was conducted by a rheumatologist, while it was not known who made the diagnosis in almost $60 \%$ of the cases.

Overall 32,244 patients had at least 1 acute gout episode recorded in the database during the follow-up period (mean follow-up (SD) was 2.16 (1.45) years). According to the operational definition of flare used, in the 12 months of follow-up after the first occurrence of a gout claim (starting 30 days after index date) $11 \%$ of 
Table 1 Demographic characteristics of gout patients (N $=177,637)$

\begin{tabular}{|c|c|c|}
\hline & $\mathrm{N}$ & $\%$ \\
\hline Male gender & 134,333 & $75.6 \%$ \\
\hline \multicolumn{3}{|l|}{ Age in categories } \\
\hline $20-49$ & 59,371 & $33.4 \%$ \\
\hline $50-59$ & 54,612 & $30.7 \%$ \\
\hline $60-69$ & 37,016 & $20.8 \%$ \\
\hline $70-79$ & 19,790 & $11.1 \%$ \\
\hline $80-89$ & 6,848 & $3.9 \%$ \\
\hline \multicolumn{3}{|l|}{ Comorbidities: } \\
\hline Cardiometabolic & 91,203 & $51.3 \%$ \\
\hline Congestive Heart Failure & 7,467 & $4.2 \%$ \\
\hline Ischemic Heart Disease & 18,066 & $10.2 \%$ \\
\hline Hypertension & 64,094 & $36.1 \%$ \\
\hline Conduction and rhythm disorder & 12,034 & $6.8 \%$ \\
\hline Cerebrovascular disease & 4,934 & $2.8 \%$ \\
\hline Peripheral arterial disease & 6,271 & $3.5 \%$ \\
\hline Chronic renal impairment & 5,718 & $3.2 \%$ \\
\hline Dyslipidemia & 47,960 & $27.0 \%$ \\
\hline Diabetes & 26,818 & $15.1 \%$ \\
\hline Gastrointestinal & 14,224 & $8.0 \%$ \\
\hline Gastrointestinal & 11,836 & $6.7 \%$ \\
\hline Hepatic disorders & 2,718 & $1.5 \%$ \\
\hline Pancreatic disorders & 501 & $0.3 \%$ \\
\hline Haematological (Anemia) & 3,829 & $2.2 \%$ \\
\hline Myopathy & 159 & $0.1 \%$ \\
\hline Arthritis & 25,516 & $14.4 \%$ \\
\hline Osteoporosis & 5,044 & $2.8 \%$ \\
\hline Any comorbidity & 103,281 & $58.1 \%$ \\
\hline \multicolumn{3}{|l|}{ Gout diagnosis recorded by: } \\
\hline Primary care physician & 56,512 & $31.8 \%$ \\
\hline Rheumatologist & 4,731 & $2.7 \%$ \\
\hline Emergency visit & 10,482 & $5.9 \%$ \\
\hline Other or Unknown specialty & 105,912 & $59.6 \%$ \\
\hline Hospitalized in 12 months follow-up (at least once) & 2,119 & $1.2 \%$ \\
\hline Outpatient visit in 12 months follow-up (at least once) & 65,665 & $37.0 \%$ \\
\hline \multicolumn{3}{|l|}{ Number of flares in 12 months follow-up: } \\
\hline 0 & 158,268 & $89.1 \%$ \\
\hline 1 & 15,893 & $9.0 \%$ \\
\hline 2 & 2,790 & $1.6 \%$ \\
\hline 3 or more & 686 & $0.4 \%$ \\
\hline
\end{tabular}

patients $(\mathrm{N}=19,369)$ had experienced one or more flares.

Table 2 shows the gout related drugs utilization for the whole cohort and separately for men and women in the 12 month of follow-up. Nonselective NSAIDs were the most commonly dispensed $(38.7 \%$ ever used them: $40.5 \%$ of men and $33.3 \%$ of women), followed by allopurinol (35.5\%), corticosteroids (20.4\%) and colchicine $(18.3 \%)$ in men; and corticosteroids (22.7\%), allopurinol $(20.6 \%)$ and colchicine $(11.8 \%)$ in women. Notably, $39 \%$ of patients (36.9\% of men and $45.3 \%$ of women) did not receive any prescription medication for gout.

Patients with cardiometabolic comorbidities were significantly more likely to be dispensed selective NSAIDs (7.9\% vs $5.5 \%)$, colchicine ( $17.6 \%$ vs $15.6 \%)$, corticosteroids $(22.5 \%$ vs $19.1 \%)$ and allopurinol (32.6\% vs $31.2 \%)$ than gout patients with no comorbidites (all $\mathrm{p}<0.0001$ after adjusting for age). This was true for both genders. Patients with diabetes and cardiovascular comorbidities had similar patterns of anti-gout treatment prescriptions. Compared with those with no comorbidities, patients with renal impairment were less likely to be dispensed nonselective NSAIDs (17.5\%), and more likely to receive allopurinol (43.9\%), colchicine $(27.3 \%)$ and corticosteroids $(28.3 \%)$ (all p-values $<0.0001$ ).

Table 3 shows the gout related drugs dispensed in the 7 days after any flare. During a flare the prescription of NSAIDs and colchicine increased. Almost a third (29.9\%) of patients received allopurinol during an acute attack.

Patients with acute attacks were also more likely to receive treatment within 12 months following the index date, compared with the gout population who did not experience flares, as shown in Table 4. In particular, the corresponding numbers dispensed colchicine among patients with no, 1,2 , and 3 or more flares were $12.2 \%$, $49.9 \%, 66.5 \%$ and $80 \%$ respectively. $27.9 \%$ of patients with no flares received allopurinol during the 12 months of follow-up, vs. $60.8 \%, 77.8 \%$ and $87.8 \%$ of patients with 1,2 , and 3 or more flares respectively. Patients with 3 or more flares were also more likely to be dispensed corticosteroids (70.6\%) than those with 1 flare (45.7\%) (Table 4).

Table 5 shows the results of the multivariable analysis. The risk of flares was associated with older age in women (highest at age 60-69), while in men it decreased by age. It was also positively associated with cardiometabolic comorbidities. Women with these conditions were $60 \%$ more likely to have flares (incidence rate ratio, IRR $1.60 ; 1.48-1.74$ ), while men were $10 \%$ more likely (IRR $1.10 ; 1.06-1.13)$. Gastrointestinal diseases were negatively associated with flares in women (IRR 0.86; 0.78-0.96) while a positive association was seen in men (IRR 1.07; 1.02-1.13). (Table 5).

When use of diuretics was entered in the model it showed a positive association with flares both in women (IRR 4.34; 4.03-4.68) and in men (IRR 1.9 1; 1.50-1.98) (data not shown).

\section{Discussion}

This study, based on a US administrative claims database, examined prescription patterns, comorbidities and flares determinants in a very large population of gout patients. In line with current guidelines [5], NSAIDs and 
Table 2 Gout related treatment patterns overall and by presence of comorbidities

\begin{tabular}{|c|c|c|c|c|c|c|c|c|c|c|c|}
\hline \multirow{3}{*}{$\begin{array}{l}\text { Gout-related medication } \\
\text { ALL }\end{array}$} & \multicolumn{11}{|c|}{ Ever use during 1 year after gout diagnosis } \\
\hline & \multicolumn{2}{|c|}{ All } & \multicolumn{2}{|c|}{$\begin{array}{l}\text { No comorbidities } \\
(n=74,356)\end{array}$} & \multicolumn{2}{|c|}{$\begin{array}{c}\text { Cardiometabolic } \S \\
(n=64,385)\end{array}$} & \multirow[b]{2}{*}{ p-value* } & \multicolumn{2}{|c|}{$\begin{array}{c}\text { Diabetes } \\
(n=26,818)\end{array}$} & \multicolumn{2}{|c|}{$\begin{array}{l}\text { Chronic renal impairment } \\
\qquad(\mathrm{n}=5,718)\end{array}$} \\
\hline & $\mathrm{n}$ & $\%$ & $\mathbf{n}$ & $\%$ & $\mathrm{n}$ & $\%$ & & n & $\%$ & n & $\%$ \\
\hline NSAIDS & 74,055 & $41.7 \%$ & 32,701 & $44.0 \%$ & 25,994 & $40.4 \%$ & 0.022 & 9,592 & $35.8 \%$ & 1,134 & $19.8 \%$ \\
\hline selective & 12,455 & $7.0 \%$ & 4,102 & $5.5 \%$ & 5,077 & $7.9 \%$ & $<.0001$ & 1,942 & $7.2 \%$ & 219 & $3.8 \%$ \\
\hline nonselective & 68,826 & $38.7 \%$ & 31,167 & $41.9 \%$ & 23,765 & $36.9 \%$ & 0.173 & 8,660 & $32.3 \%$ & 1,001 & $17.5 \%$ \\
\hline Colchicine & 29,686 & $16.7 \%$ & 11,595 & $15.6 \%$ & 11,327 & $17.6 \%$ & $<.0001$ & 4,950 & $18.5 \%$ & 1,559 & $27.3 \%$ \\
\hline Corticosteroids & 37,224 & $21.0 \%$ & 14,182 & $19.1 \%$ & 14,476 & $22.5 \%$ & $<.0001$ & 5,153 & $19.2 \%$ & 1,617 & $28.3 \%$ \\
\hline Probenecid & 2,510 & $1.4 \%$ & 1,108 & $1.5 \%$ & 901 & $1.4 \%$ & 0.249 & 331 & $1.2 \%$ & 58 & $1.0 \%$ \\
\hline Allopurinol & 56,544 & $31.8 \%$ & 23,215 & $31.2 \%$ & 20,971 & $32.6 \%$ & $<.0001$ & 9,183 & $34.2 \%$ & 2,512 & $43.9 \%$ \\
\hline No treatment & 69,241 & $39.0 \%$ & 29,202 & $39.3 \%$ & 24,938 & $38.7 \%$ & $<.0001$ & 10,669 & $39.8 \%$ & 2,171 & $38.0 \%$ \\
\hline FEMALES & \multicolumn{2}{|c|}{$N=43,304$} & \multicolumn{2}{|c|}{$N=12,387$} & \multicolumn{2}{|c|}{$N=17,418$} & & \multicolumn{2}{|c|}{$N=9,381$} & \multicolumn{2}{|c|}{$N=2,025$} \\
\hline NSAIDS & 16,183 & $37.4 \%$ & 4,641 & $37.5 \%$ & 6,464 & $37.1 \%$ & $<.0001$ & 3,279 & $35.0 \%$ & 368 & $18.2 \%$ \\
\hline selective & 3,815 & $8.8 \%$ & 911 & $7.4 \%$ & 1,643 & $9.4 \%$ & $<.0001$ & 769 & $8.2 \%$ & 77 & $3.8 \%$ \\
\hline nonselective & 14,423 & $33.3 \%$ & 4,255 & $34.4 \%$ & 5,684 & $32.6 \%$ & 0.000 & 2,899 & $30.9 \%$ & 320 & $15.8 \%$ \\
\hline Colchicine & 5,096 & $11.8 \%$ & 890 & $7.2 \%$ & 2,312 & $13.3 \%$ & $<.0001$ & 1,558 & $16.6 \%$ & 483 & $23.9 \%$ \\
\hline Corticosteroids & 9,831 & $22.7 \%$ & 2,438 & $19.7 \%$ & 4,213 & $24.2 \%$ & $<.0001$ & 1,954 & $20.8 \%$ & 575 & $28.4 \%$ \\
\hline Probenecid & 441 & $1.0 \%$ & 96 & $0.8 \%$ & 195 & $1.1 \%$ & 0.359 & 115 & $1.2 \%$ & 27 & $1.3 \%$ \\
\hline Allopurinol & 8,905 & $20.6 \%$ & 1,676 & $13.5 \%$ & 4,006 & $23.0 \%$ & $<.0001$ & 2,692 & $28.7 \%$ & 834 & $41.2 \%$ \\
\hline No treatment & 19,637 & $45.3 \%$ & 6,200 & $50.1 \%$ & 7,693 & $44.2 \%$ & $<.0001$ & 3,991 & $42.5 \%$ & 816 & $40.3 \%$ \\
\hline MALES & \multicolumn{2}{|c|}{$N=134,333$} & \multicolumn{2}{|c|}{$N=61,969$} & \multicolumn{2}{|c|}{$N=46,967$} & & \multicolumn{2}{|c|}{$\mathrm{N}=17,437$} & \multicolumn{2}{|c|}{$N=3,693$} \\
\hline NSAIDS & 57,872 & $43.1 \%$ & 28,060 & $45.3 \%$ & 19,530 & $41.6 \%$ & 0.575 & 6,313 & $36.2 \%$ & 766 & $20.7 \%$ \\
\hline selective & 8,640 & $6.4 \%$ & 3,191 & $5.1 \%$ & 3,434 & $7.3 \%$ & $<.0001$ & 1,173 & $6.7 \%$ & 142 & $3.8 \%$ \\
\hline nonselective & 54,403 & $40.5 \%$ & 26,912 & $43.4 \%$ & 18,081 & $38.5 \%$ & 0.012 & 5,761 & $33.0 \%$ & 681 & $18.4 \%$ \\
\hline Colchicine & 24,590 & $18.3 \%$ & 10,705 & $17.3 \%$ & 9,015 & $19.2 \%$ & $<.0001$ & 3,392 & $19.5 \%$ & 1,076 & $29.1 \%$ \\
\hline Corticosteroids & 27,393 & $20.4 \%$ & 11,744 & $19.0 \%$ & 10,263 & $21.9 \%$ & $<.0001$ & 3,199 & $18.3 \%$ & 1,042 & $28.2 \%$ \\
\hline Probenecid & 2,069 & $1.5 \%$ & 1,012 & $1.6 \%$ & 706 & $1.5 \%$ & 0.260 & 216 & $1.2 \%$ & 31 & $0.8 \%$ \\
\hline Allopurinol & 47,639 & $35.5 \%$ & 21,539 & $34.8 \%$ & 16,965 & $36.1 \%$ & $<.0001$ & 6,491 & $37.2 \%$ & 1,678 & $45.4 \%$ \\
\hline No treatment & 49,604 & $36.9 \%$ & 23,002 & $37.1 \%$ & 17,245 & $36.7 \%$ & $<.0001$ & 6,678 & $38.3 \%$ & 1,355 & $36.7 \%$ \\
\hline
\end{tabular}

$\S$ Cardiometabolic disease include congestive heart failure, ischaemic heart disease, hypertension, cerebrovascular disease, peripheral arterial disease, dyslipidemia.

* P-value from logistic model with drug as outcome associated to cardiometabolic comorbidities vs no comorbidities adjusting for age in categories (20-49, 50$59,60-69,70-79,80-89)$.

colchicine were the drugs most commonly prescribed during an acute attack. However our data suggest that somewhat suboptimal treatment and management may occur in clinical practice: almost a third of patients received ULT during an acute attack and 39\% of patients did not receive any prescription medication for gout. Cardiometabolic comorbidities in particular were associated with gout treatment patterns and were also associated with a high burden of disease, as reflected by an increased risk of flares.

Gout treatment has been shown to be suboptimal in two studies from the US $[10,11]$ and a study from the UK [12]. According to our data, gout treatment was relying mostly on traditional treatment means such as NSAIDs to control inflammation and pain. Corticosteroids and colchicine were dispensed in about a fifth of patients while ULT, recommended as the treatment to prevent further acute attacks, was dispensed in less than a third of all gout patients and probenecid was seldom dispensed. Probenecid use was also described as infrequent in a study based on US ambulatory care data [13]. Here the authors, basing their study on a national probability sample survey of physicians-patients encounters, showed a larger overall utilisation of allopurinol in patients with gout than in our study. Differences in estimates may be related to differences in data collection methods and patients characteristics (e.g. age and geographic location). For example, the age distribution of this patient population appeared to be younger compared to other studies. On average, only $12 \%$ of the PharMetrics population was aged 60-89. This may make the results of our study less generalizable to the gout population overall, however consistent with the age distribution in other health care plans [14].

NSAIDs have been reported as the drug of first choice to treat acute gout attacks in the US [2] and in other 
Table 3 Treatment patterns for treatment of flares occurring at any time during the study period

\begin{tabular}{|c|c|c|}
\hline \multicolumn{3}{|c|}{ Gout drugs within 7 days of flare } \\
\hline & \multicolumn{2}{|c|}{ (any flare) $n=32,244$} \\
\hline & $\mathrm{n}$ & $\%$ \\
\hline NSAIDS & 21,633 & $67.1 \%$ \\
\hline selective & 1,283 & $4.0 \%$ \\
\hline nonselective & 20,748 & $64.3 \%$ \\
\hline Colchicine & 12,847 & $39.8 \%$ \\
\hline Corticosteroids & 8,598 & $26.7 \%$ \\
\hline Probenecid & 420 & $1.3 \%$ \\
\hline Allopurinol & 9,644 & $29.9 \%$ \\
\hline No treatment & 0 & $0.0 \%$ \\
\hline
\end{tabular}

countries [12]. These drugs are, however, associated with gastrointestinal, renal and cardiovascular effects and it was not surprising that in our study patients with cardiometabolic comorbidities, and in particular those with chronic renal impairment, had the prescription of NSAIDs greatly reduced. It is notable that almost two fifths of patients did not receive any prescription within 12 months from the index date. These patients may have had fewer flares, i.e. less severe manifestation of the disease, may have had medication still at home, or been able to purchase over the counter medications to reduce their symptoms, since non-prescription medications would not be recorded in the database.

Given that hyperuricemia is the most important single risk factor for gout, the long-term management of hyperuricemia to prevent further attacks and complications of the disease is an important component of the therapeutic regimen. The use of ULT is recommended after the acute episode has subsided [5], however according to our data almost a third of patients received a prescription of allopurinol during an acute attack. An increased number of flares during the 12 months from the first occurrence of a gout claim seemed to have resulted in more aggressive treatment
Table 5 Poisson multivariate regression model for number of flares during follow-up of $\mathbf{1 2}$ months by sex

\begin{tabular}{|c|c|c|c|c|c|c|c|}
\hline & & \multicolumn{3}{|c|}{$\begin{array}{c}\text { Females } \\
(\mathrm{N}=43,304)\end{array}$} & \multicolumn{3}{|c|}{ Males $(\mathrm{N}=134,333)$} \\
\hline & & IRR & $95 \% \mathrm{Cl}$ & $\begin{array}{l}\mathrm{p}- \\
\text { value }\end{array}$ & IRR & $95 \% \mathrm{Cl}$ & $\begin{array}{c}\mathrm{p}- \\
\text { value }\end{array}$ \\
\hline \multirow[t]{5}{*}{ Age } & $<50$ & 1.00 & (ref.) & & 1.00 & (ref.) & \\
\hline & $\begin{array}{l}50- \\
59\end{array}$ & 1.66 & $\begin{array}{l}(1.49 \\
1.85)\end{array}$ & $\begin{array}{l}< \\
.0001\end{array}$ & 0.83 & $\begin{array}{l}(0.80 \\
0.85)\end{array}$ & $\begin{array}{c}< \\
.0001\end{array}$ \\
\hline & $\begin{array}{l}60- \\
69\end{array}$ & 1.93 & $\begin{array}{l}(1.73 \\
2.16)\end{array}$ & $\begin{array}{l}< \\
.0001\end{array}$ & 0.76 & $\begin{array}{l}(0.73 \\
0.79)\end{array}$ & $\begin{array}{c}< \\
.0001\end{array}$ \\
\hline & $\begin{array}{l}70- \\
79\end{array}$ & 1.69 & $\begin{array}{l}(1.51 \\
1.90)\end{array}$ & $\begin{array}{l}< \\
.0001\end{array}$ & 0.56 & $\begin{array}{l}(0.53 \\
0.60)\end{array}$ & $\begin{array}{c}< \\
.0001\end{array}$ \\
\hline & $\begin{array}{l}80- \\
89\end{array}$ & 1.31 & $\begin{array}{l}(1.12, \\
1.52)\end{array}$ & 0.001 & 0.53 & $\begin{array}{l}(0.48 \\
0.59)\end{array}$ & $\begin{array}{c}< \\
.0001\end{array}$ \\
\hline \multicolumn{8}{|l|}{ Comorbidities: } \\
\hline Cardiometabolic* & & 1.60 & $\begin{array}{l}(1.48 \\
1.74)\end{array}$ & $\begin{array}{l}< \\
.0001\end{array}$ & 1.10 & $\begin{array}{l}(1.06 \\
1.13)\end{array}$ & $\begin{array}{c}< \\
.0001\end{array}$ \\
\hline Diabetes & & 1.48 & $\begin{array}{l}(1.35 \\
1.63)\end{array}$ & $\begin{array}{l}< \\
.0001\end{array}$ & 0.97 & $\begin{array}{l}(0.93 \\
1.02)\end{array}$ & 0.262 \\
\hline Gastrointestinal & & 0.86 & $\begin{array}{l}(0.78 \\
0.96)\end{array}$ & 0.005 & 1.07 & $\begin{array}{l}(1.02, \\
1.13)\end{array}$ & 0.011 \\
\hline Hematological & & 1.03 & $\begin{array}{l}(0.88 \\
1.20)\end{array}$ & 0.720 & 0.94 & $\begin{array}{l}(0.84 \\
1.06)\end{array}$ & 0.340 \\
\hline Myopathy & & 1.21 & $\begin{array}{l}(0.50 \\
2.91)\end{array}$ & 0.670 & 0.84 & $\begin{array}{l}(0.50 \\
1.42)\end{array}$ & 0.509 \\
\hline Osteoporosis & & 0.88 & $\begin{array}{l}(0.78 \\
1.00)\end{array}$ & 0.044 & 1.11 & $\begin{array}{l}(0.99 \\
1.25)\end{array}$ & 0.076 \\
\hline
\end{tabular}

IRR = Incidence rate ratio.

* Cardiometabolic disease include congestive heart failure, ischaemic heart disease, hypertension, cerebrovascular disease, peripheral arterial disease, dyslipidemia.

patterns. In particular, more than three times as many patients with 3 or more flares were dispensed corticosteroids or allopurinol compared with patients with no flares. This may reflect the fact that in patients with more severe disease (using number of flares as an indicator of disease severity) the available therapeutic regimen was not adequate to prevent further acute attacks, and the treating physician had to step up the treatment.

Table 4 Treatment patterns: patients with no flares and with flares occurring during follow-up of 12 months ( $N=19,369)$

\begin{tabular}{|c|c|c|c|c|c|c|c|c|c|c|}
\hline \multirow[t]{2}{*}{$\begin{array}{l}\text { Ever during } 12 \text { months } \\
\text { after index date }\end{array}$} & \multicolumn{2}{|c|}{ No flares } & \multicolumn{2}{|c|}{$\begin{array}{c}\text { Total (any flare) } \\
(\mathrm{n}=19,369)\end{array}$} & \multicolumn{2}{|c|}{$\begin{array}{c}1 \text { flare } \\
(n=15,893)\end{array}$} & \multicolumn{2}{|c|}{$\begin{array}{c}2 \text { flares } \\
(\mathrm{n}=2,790)\end{array}$} & \multicolumn{2}{|c|}{$\begin{array}{c}3 \text { flares } \\
(\mathrm{n}=686)\end{array}$} \\
\hline & $\mathrm{n}$ & $\%$ & $\mathrm{n}$ & $\%$ & $\mathrm{n}$ & $\%$ & $\mathrm{n}$ & $\%$ & $\mathrm{n}$ & $\%$ \\
\hline NSAIDS & 58325 & $36.9 \%$ & 15730 & $81.2 \%$ & 12821 & $80.7 \%$ & 2338 & $83.8 \%$ & 571 & $83.2 \%$ \\
\hline selective & 10110 & $6.4 \%$ & 2345 & $12.1 \%$ & 1795 & $11.3 \%$ & 430 & $15.4 \%$ & 120 & $17.5 \%$ \\
\hline nonselective & 53750 & $34.0 \%$ & 15076 & $77.8 \%$ & 12278 & $77.3 \%$ & 2245 & $80.5 \%$ & 553 & $80.6 \%$ \\
\hline Colchicine & 19353 & $12.2 \%$ & 10333 & $53.3 \%$ & 7929 & $49.9 \%$ & 1855 & $66.5 \%$ & 549 & $80.0 \%$ \\
\hline Corticosteroids & 28379 & $17.9 \%$ & 8845 & $45.7 \%$ & 6695 & $42.1 \%$ & 1666 & $59.7 \%$ & 484 & $70.6 \%$ \\
\hline Probenecid & 1781 & $1.1 \%$ & 729 & $3.8 \%$ & 503 & $3.2 \%$ & 174 & $6.2 \%$ & 52 & $7.6 \%$ \\
\hline Allopurinol & 44110 & $27.9 \%$ & 12434 & $64.2 \%$ & 9662 & $60.8 \%$ & 2170 & $77.8 \%$ & 602 & $87.8 \%$ \\
\hline No treatment & 69241 & $43.7 \%$ & 0 & $0.0 \%$ & 0 & $0.0 \%$ & 0 & $0.0 \%$ & 0 & $0.0 \%$ \\
\hline
\end{tabular}


The association between cardiovascular disease and gout, including significant cardiovascular mortality risk, is well recognised [15-17]. EULAR guidelines therefore recommend screening for cardiovascular risk and treating comorbid conditions in gout patients [5]. Our study demonstrated that cardiometabolic comorbidities were frequent in this patient population. They impacted the prescription patterns, since these patients were more likely to be prescribed corticosteroids, colchicine, selective NSAIDs and allopurinol than patients with no comorbidities. The increased use of selective NSAIDs in patients with cardiometabolic comorbidities is somewhat counterintuitive given their potential cardiovascular risk (although data collection partly preceded recent cardiovascular concerns), even though the EULAR guidelines are still open on this issue [5]. Regarding the increased use of allopurinol in patients with cardiometabolic comorbidities, this may also be considered to go against clinical judgement, in particular considering its potential toxicity in patients with impaired renal function and the potential for drug interaction (e.g. warfarin). Whether allopurinol should be prescribed at reduced dosage in patients with impaired renal function remains however still controversial [5]. These patients were also at increased risk of flares. The use of diuretics is a recognised risk factor for gout. Although contraindicated [5], these medications are commonly prescribed in this patients' population, and this may increase their risk of flares.

Women with gastrointestinal diseases were at reduced risk of flares while in men the association was in the opposite direction. This observation has not been made before and should get further consideration in future studies.

Patients with renal impairment were less likely to be prescribed NSAIDs than gout patients without comorbidities, and more likely to receive allopurinol, colchicine and corticosteroids. It is recommended that these patients receive a lower dose of allopurinol given that they are at increased risk of toxic effects [14]. Providing adequate information to these patients regarding the risks and benefits at different dosages would be advisable.

Limitations of a study based on an administrative claims database need to be considered. Firstly, these data only apply to patients with a commercial insurance and these findings may therefore not be generalisable to gout patients without commercial insurance. Further, the diagnosis of gout was not confirmed using medical record review. To increase the sensitivity and specificity of the gout identification algorithm, a patient was only classified as a gout patient if two distinct medical encounters with a diagnosis of gout were present in the record. This would reduce the potential for including in the study patients without gout. Currently there is no validated epidemiological definition of gout flare, and although we followed the definition used by other authors (cfr e.g. ref [14]), based on clinical measurements, we expect that some errors of sensitivity (failure to identify true gout flares) and specificity (identification of subjects who did not experience gout flares) may be inherent in the definition. Specifically, some patients may, when starting ULT, have received NSAIDs, colchicine and, less commonly, steroids as prophylaxis against acute attacks and this may have lead to an overestimation of flares. However, by excluding those who commenced allopurinol treatment within 7 days before a flare the number of patients with flares would not have changed substantially (19,267 vs 19,369 observed).

It is also recognised that many patients with gout flares do not consult their physician [11], and may selfmanage acute episodes. This is likely to be the case in the present study, given that the risk of gout flares reported over one year follow-up (10.9\%) is lower than what other studies have shown [18]. It was also not possible to verify that the drugs included were dispensed for gout and to assess adherence to the prescribed treatment. Nevertheless, epidemiological studies such as the present one, which included a very large number of patients with gout, with a large US geographic distribution, can improve our understanding of management of gout in real world settings.

\section{Conclusions}

In conclusion, results from the analysis of data from this large administrative claims database are supporting suggestions from other studies [10-12], i.e. that suboptimal treatment and management of gout may occur in clinical practice. In addition, cardiometabolic comorbidities, common in this patient population, were associated with a higher burden of disease, as reflected by an increased risk of flares.

\section{Acknowledgements and Funding}

The study was conducted at Novartis Pharma AG and Novartis Farmaceutica SA jointly. The study was funded by Novartis Farmacéutica SA.

\section{Author details}

${ }^{1}$ Global Clinical Epidemiology, Novartis Pharma AG, CH-4056 Basel, Switzerland. ${ }^{2}$ Global Clinical Epidemiology, Novartis Farmacéutica SA, Barcelona, Spain. ${ }^{3}$ Institute for Epidemiology and Medical Biometry, University of UIm, Ulm, Germany.

\section{Authors' contributions}

PP conceived of the study, participated in its design and drafted the manuscript. She is responsible for the whole study. EP participated in the design of the study and performed the statistical analysis. DR participated in the design of the study and helped to draft the manuscript. All authors read and approved the final manuscript.

\section{Competing interests}

PP and EP are employees of Novartis Pharma. 


\section{References}

1. Richette P, Bardin T: Gout. Lancet 2010, 375:318-28.

2. Kim KY, Schumacher HR, Hunsche E, Wertheimer Al, Kong SH: A literature review of the epidemiology and treatment of acute gout. Clin Ther 2003, 25:1593-617.

3. Suresh E: Diagnosis and management of gout: a rational approach. Postgrad Med J 2005, 81:572-79.

4. Cronstein BN, Terkeltaub R: The inflammatory process of gout and its treatment. Arthritis Res Ther 2006, 8(Suppl 1):S3.

5. Zhang W, Doherty M, Pascual E, Bardin T, Barskova V, Conaghan P, Gerster J, Jacobs J, Leeb B, McCarthy G, Netter P, Nuki G, Perez-Ruiz F, Pignone A, Pimentao J, Punzi L, Roddy E, Uhlig T, Zimmermann-Gorska I: EULAR Evidence based recommendations for gout. Parts I and II. Ann Rheum Dis 2006, 65:1301-24.

6. Jordan KM, Cameron JS, Snaith M, Zhang W, Doherty M, Seckl J, Hingorani A, Jacques R, Nuki G: British Society for Rheumatology and British Health Professionals in Rheumatology guideline for the management of gout. Rheumatology (Oxford) 2007, 46:1372-74.

7. Roddy E, Zhang W, Doherty M: Concordance of the management of chronic gout in a UK primary-care population with the EULAR gout recommendations. Ann Rheum Dis 2007, 66:1311-15.

8. Fels E, Sundy JS: Refractory gout: what is it and what to do about it? Curr Opin Rheumatol 2008, 20:198-202

9. Pascual E, Sivera F: Why is gout so poorly managed? Ann Rheum Dis 2007, 66:1269-70.

10. Singh JA, Hodges JS, Asch SM: Opportunities for improving medication use and monitoring in gout. Ann Rheum Dis 2009, 68:1265-70.

11. Neogi T, Hunter DJ, Chaisson CE, Allensworth-Davies D, Zhang Y: Frequency and predictors of inappropriate management of recurrent gout attacks in a longitudinal study. J Rheumatol 2006, 33:104-09.

12. Roddy E, Mallen CD, Hider SL, Jordan KP: Prescription and comorbidity screening following consultation for acute gout in primary care. Rheumatology 2010, 49:105-11.

13. Krishnan E, Lienesch D, Kwoh CK: Gout in ambulatory care settings in the United States. J Rheumatol 2008, 35:498-501.

14. Sarawate CA, Brewer KK, Yang E, Patel PA, Schumacher HR, Saag KG, Bakst AW: Gout treatment patterns and adherence to standards of care from managed care perspective. Mayo Clin Proc 2006, 81:925-34.

15. Krishnan E, Svendsen K, Neaton JD, Grandits G, Kuller LH: Long-term cardiovascular mortality among middle-aged men with gout. Arch Intern Med 2008, 168:1104-10.

16. Krishnan E, Baker JF, Furst DE, Schumacher HR: Gout and the risk of acute myocardial infarction. Arthritis Rheum 2006, 54:2688-96.

17. Mikuls TR, Farrar JT, Bilker WB, Fernandes S, Schumacher HR, Saag KG: Gout epidemiology: results from the UK General Practice Research Database, 1990-1999. Ann Rheum Dis 2005, 64:267-72.

18. Sarawate CA, Patel PA, Schumacher DHR, Yang W, Brewer KK, Bakst AW: Serum urate levels and gout flares: Analysis from managed care data. $J$ Clin Rheumatol 2006, 12:61-65.

\section{Pre-publication history}

The pre-publication history for this paper can be accessed here: http://www.biomedcentral.com/1471-2474/12/103/prepub

doi:10.1186/1471-2474-12-103

Cite this article as: Primatesta et al:: Gout treatment and comorbidities: a retrospective cohort study in a large US managed care population. BMC Musculoskeletal Disorders 2011 12:103. 